\title{
3-D Vertical Seismic Profiling at LLNL Site 300
}

\author{
R. Bainer \\ J. Rector \\ P. Milligan
}

January 29, 1997

This is an informal report intended primarily for internal or limited external distribution. The opinions and conclusions stated are those of the author and may or may not be those of the Laboratory.

Work performed under the auspices of the U.S. Department of Energy by the Lawrence Livermore National Laboratory under Contract W-7405-ENG-48. 


\section{DISCLAIMER}

This document was prepared as an account of work sponsored by an agency of the United States Covernment. Neither the United States Covernment nor the University of California nor any of their employees, makes any warranty, express or implied, or assumes any legal liability or responsibility for the accuracy, completeness, or usefuiness of any information, apparatus, product, or process disclosed, or represents that its use would not infringe privately own rights. Reference herein to any specific commercial products, process, or service by trade name, trademark, manufacturer, or otherwise, does not necessarily constitute or imply its endorsement, recommendation, or favoring by the United States Government or the University of California. The views and opinions of authors expressed herein do not necessarily state or reflect those of the United States Government or the University of California, and shall not be used for advertising or product endorsement purposes.

This report has been reproduced directly from the best available copy.

Available to DOE and DOE contractors from the Office of Scientific and Technical Information

P.O. Box 62, Oak Ridge, TN 37831

Prices available from (615) 576-8401, FTS 626-8401

Available to the public from the

National Technical Information Service

U.S. Department of Commerce

5285 Port Royal Rd.,

Springfield, VA 22161 


\section{3-D Vertical Seismic Profiling at LLNL Site 300 R. Bainer, LLNL; J. Rector, P. Milligan, U.C. Berkeley}

The initial goal of the 3-D Vertical Seismic Profiling (VSP) work at LLNL was to characterize seismic wave velocities and frequencies below the vadose zone to design the acquisition geometry for a 3-D shallow surface seismic reflection survey. VSPs are also used routinely to provide a link between surface seismic data and well logs. However, a test 2-D seismic line recorded at LLNL in the Spring of 1994 indicated that obtaining high quality reflection images below the vadose zone, yet shallower that $50 \mathrm{~m}$, would require an expensive, very finely sampled survey ( $<1 \mathrm{~m}$ receiver spacing). Extensive image processing of the LLNL 2-D test line indicated that the only reliable reflection was from the top of the water table. Surprisingly, these results were very different than recent 3-D seismic work recorded at other sites, where high quality, high frequency surface (up to $300 \mathrm{~Hz}$ ) reflection images were obtained as shallow as $20 \mathrm{~m}$. We believe that the differences are primarily due to the comparatively deep vadose zone at LLNL (15 to $30 \mathrm{~m}$ ) as compared to $0-5 \mathrm{~m}$ at other sites. The thick vadose zone attenuates the reflection signals, particularly at the high frequencies (above 100 $\mathrm{Hz}$ ). In addition, the vadose zone at LLNL creates a seismogram in which surface-propagating noise overlaps with the reflection signals for reflections above $50 \mathrm{~m}$. By contrast, when the vadose zone is not thick, high frequencies can propagate and noise will not overlap with reflections as severely.

Based on the results from the 2-D seismic line and the encouraging results from a VSP run concurrent with the 2-D seismic experiment, we modified the objectives of the research and expanded the scope of the VSP imaging at LLNL. We conducted two 3-D multi-offset VSP experiments at LLNL in the Summer and Fall of 1994. These VSP experiments were designed to characterize the seismic propagation characteristics at two different locations on the LLNL site: the first was a well with a relatively shallow water table $(10 \mathrm{~m})$, while the second was a well with a relatively deep water table (about $25 \mathrm{~m}$ ). Other goals of the VSP experiments were to characterize the velocity structure in the vicinity of boreholes, and to attempt to image reflections away from the boreholes. We found that the usable frequency content appeared to vary with water table level. At borehole B-1015, where the water table was at $10 \mathrm{~m}$, the maximum usable frequency was $300 \mathrm{hz}$. At the next well, where the water table was $25 \mathrm{~m}$, the usable frequency content was $120 \mathrm{~Hz}$. Since tube wave noise restricts the lowest usable frequency content to $150 \mathrm{~Hz}$, the B-1015 data was narrow band, with only one octave of usable bandwidth, while the other data was not usable.

To verify the dependence of frequency content on water table level, we collected 3-D VSP data at Well 35-07A at Site 300. This location was chosen because the water table was very shallow $(0$ to $5 \mathrm{~m})$, and it was expected that very high frequencies could be obtained at this location. A second goal of he survey was to characterize shallow seismic wave propagation in a sequence that consisted primarily of sand rather than the clay-dominated sequences found at the LLNL Livermore Site. 


\section{Site 300 Well W35-07A VSP Acquisition and Analysis}

We collected VSP data with two seismic sources; an 8 gauge betsy gun fired into a $1 \mathrm{~m}$ auger-drilled hole; and a sledge hammer-on-plate. For each source we used a 24 element hydrophone string to record the VSP data (hydrophone spacing was $0.5 \mathrm{~m}$ resulting in a total array length of $11.5 \mathrm{~m}$ ). The shallowest hydrophone level was about $1 \mathrm{~m}$ below the ground surface, roughly at the water table. We used a OYO Das-1 48 channel, 24 bit recording system to record the data with a 0.2 second sampling interval and a $40 \mathrm{~Hz}$ analog and digital low-cut filter.

We recorded 3 different levels with the hydrophone array, beginning at a depth of $1 \mathrm{~m}$, extending to a last hydrophone at $34.5 \mathrm{~m}$. Field data analysis displays were very limited with the OYO recording system, but with the raw displays it appeared that good data was being acquired. One problem that we could not observe in the field analysis was surface statics. When we moved the hydrophones and reoccupied the same source position, the bulk travel time shifted substantially. This was true for both the betsy gun and the hammer (although the statics of the betsy gun were more severe) indicating that the near surface velocity was highly variable in this area. Ideally, VSP data should be acquired with more hydrophones, or an expandable string, so that the entire logged zone can be recorded at once. Besides reducing acquisition time, this will eliminate changes in source signature and delay for different hydrophone moves and will reduce the spatial variability of tube waves.

Initial data processing consisted of velocity analysis, 2-D spectral analysis and synthetic acoustic seismogram generation. Figures 1 and 2 show data from the $10 \mathrm{ft}$ source offset and the $50 \mathrm{ft}$ source offset for each source type along with an acoustic synthetic for each offset using velocities obtained from the first arrival traveltime picks. These displays indicated that the first arrival energy had a wavelet width of about 2 milliseconds, indicating a bandwidth of more than $500 \mathrm{~Hz}$. For the near offset data we observed strong shear waves converted from a layer at about $3 \mathrm{~m}$ depth. The shear wave velocity ranged between 900 and $1200 \mathrm{~m} / \mathrm{s}$ and had a bandwidth that was substantially lower than the Pwave. Also evident in the near offset display were strong tube waves. For the near offset data we saw little difference between the bandwidth and the signal quality for the two sources used.

The far offset data had a slightly lower frequency content and weaker shear waves, consistent with the hydrophone reception pattern in low velocity rocks, which principally record low frequency shear waves coming from nearvertical incidence angles. The signal quality was substantially better for the betsy data than for the hammer. Figure 3 shows an $\mathrm{f}-\mathrm{k}$ display with the direct arrival aligned to zero moveout $(\mathrm{k}=0)$. The direct arrival signal has usable frequency content up to $600 \mathrm{~Hz}$, consistent with the hypothesis that water table depth 
primarily controls bandwidth. The reflection arrivals are only weakly visible in the real data, and will require wavefield separation processing to extract.

In summary, the preliminary analysis of Site $300 \mathrm{VSP}$ indicates that water table depth is the principal factor in recorded bandwidth. A stronger portable impact source such as an enhanced hammer would be a better source of energy. Also, a bigger hydrophone array would dramatically improve data quality. Future work will consist of producing a 3-D reflection image from the long offset data and tying these images into velocity and other log data. 
Finite Difference Model vs Raw Data with Static Corrections - Hammer Source at 10 feet offset

Depthe $1 \mathrm{~m}$ $97 \mathrm{~m} \quad 1 \mathrm{~m}$ $37 \mathrm{~m}$

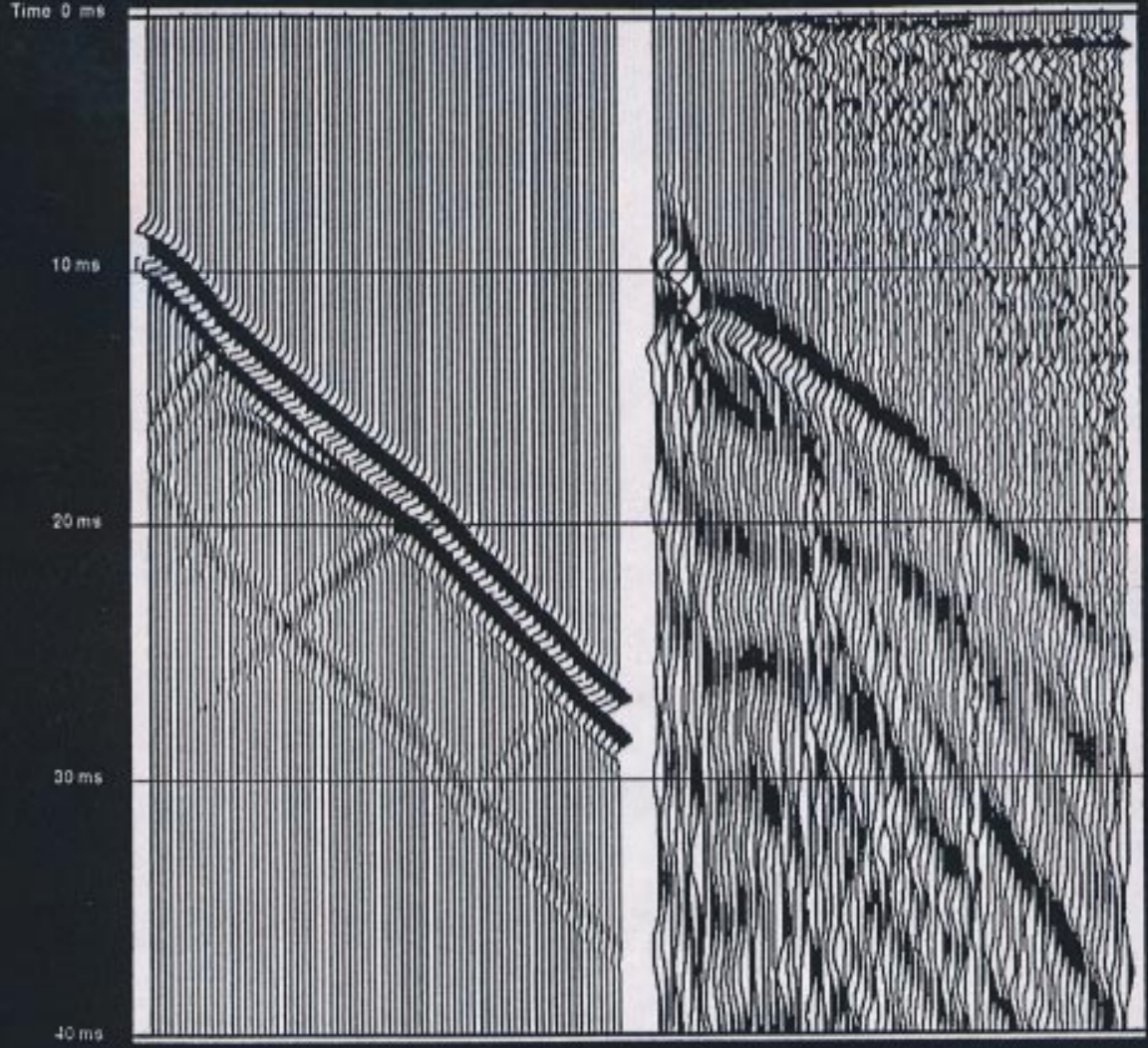

Finite Difference Model vs Raw Data with Static Corrections - Betsy Source at 10 feet offset

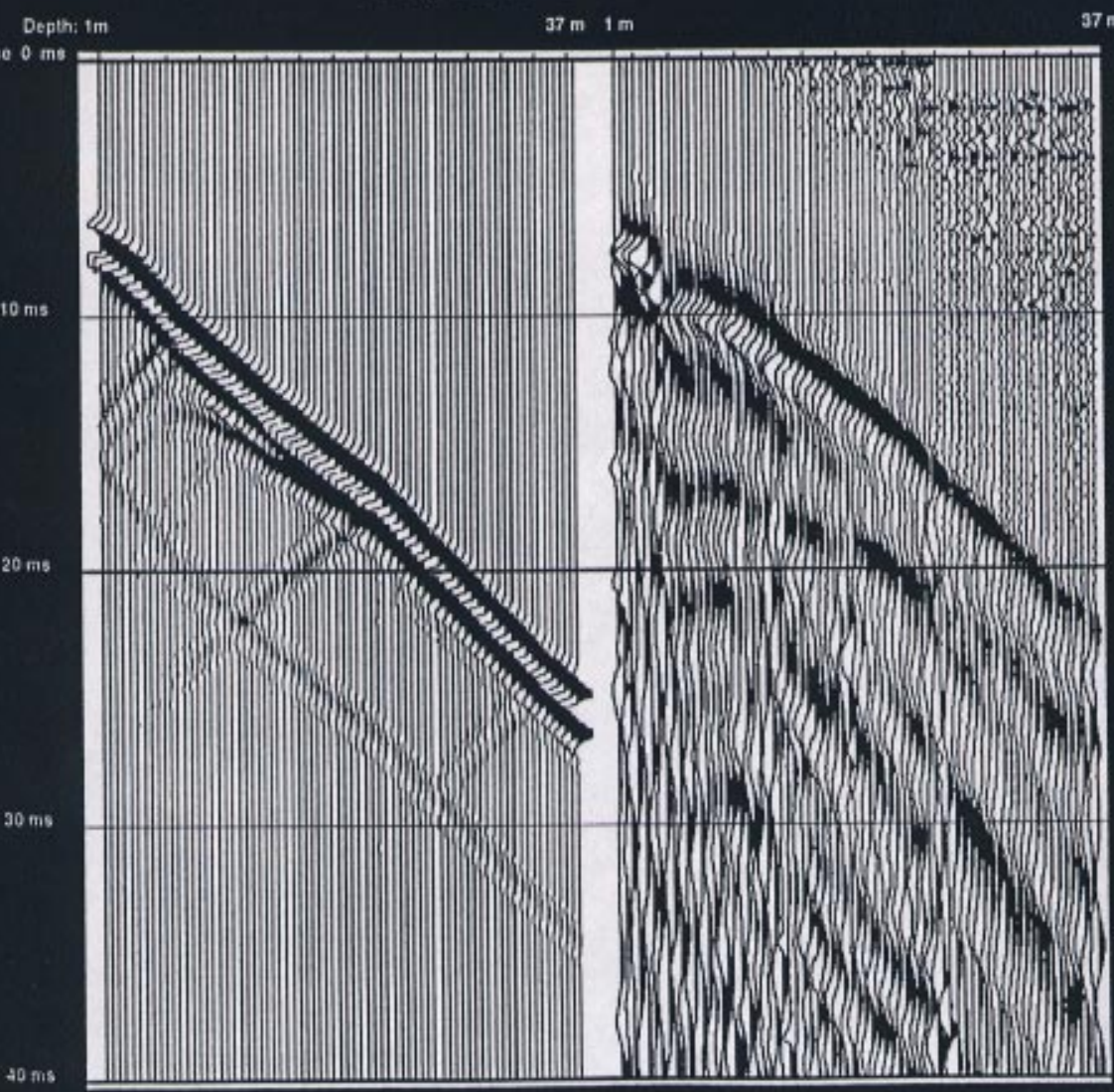


Finite Difference Model vs Raw Data with Statics Corrections - Hammer Source at 50 feet offset
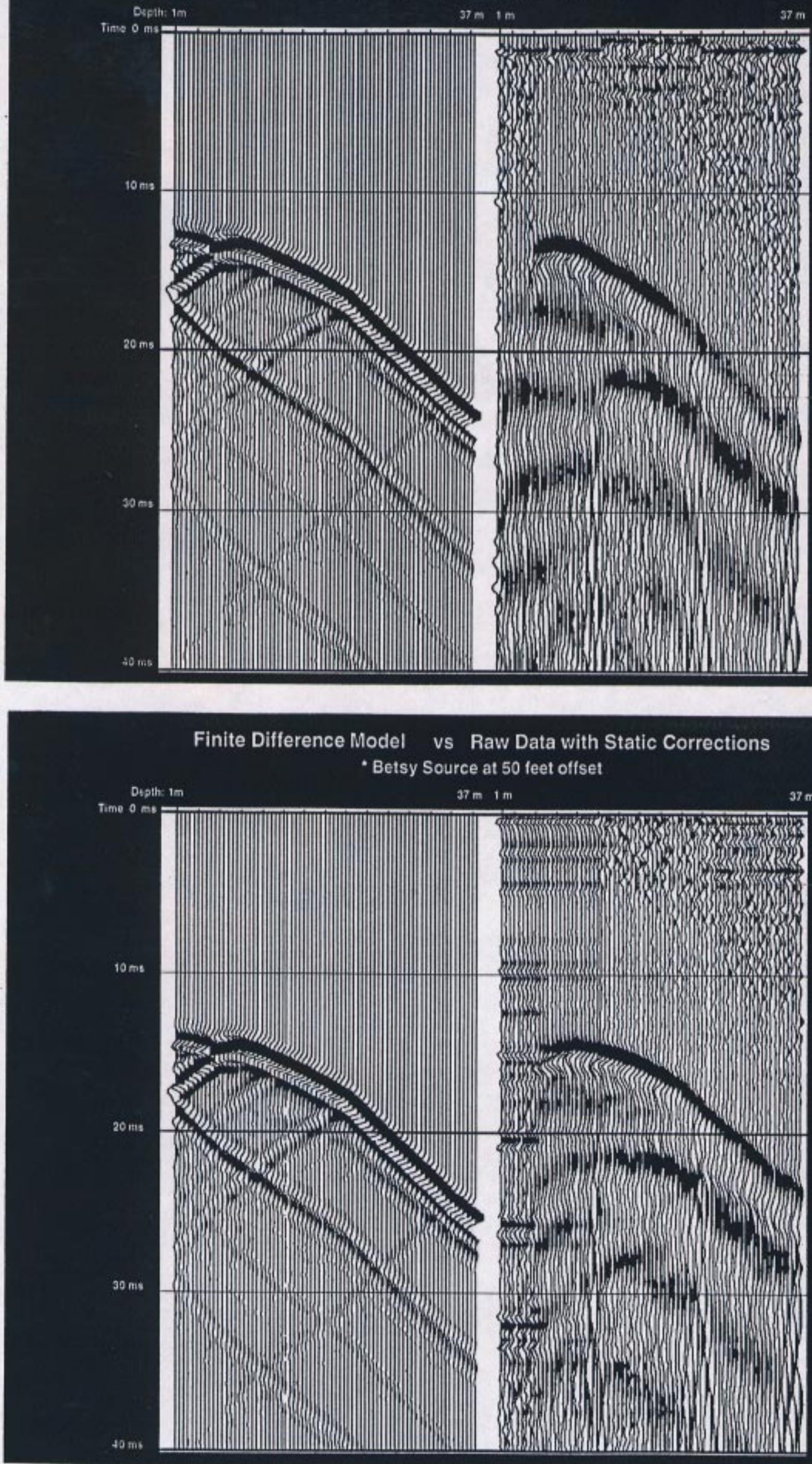
Frequency spectrum, Site 300

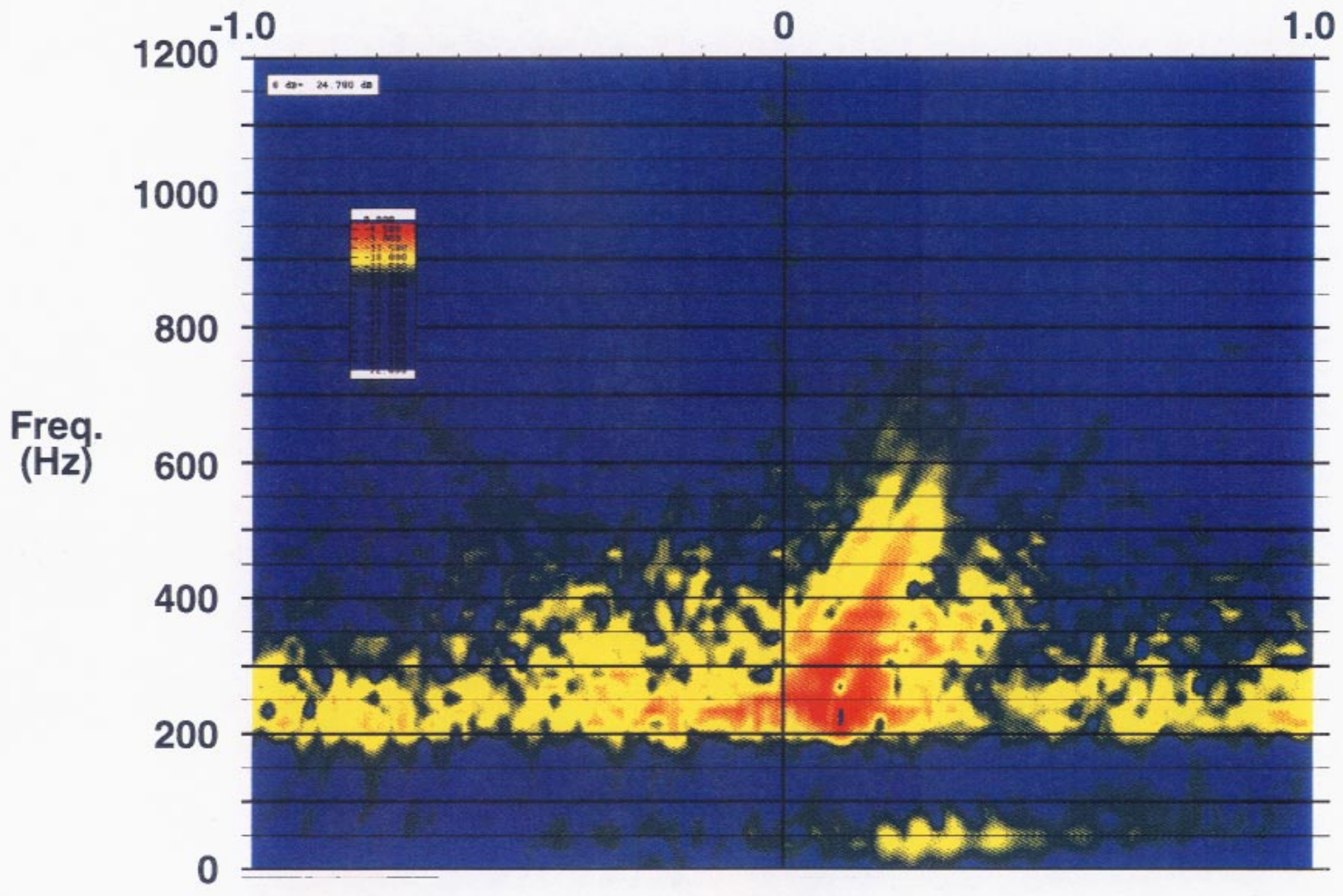




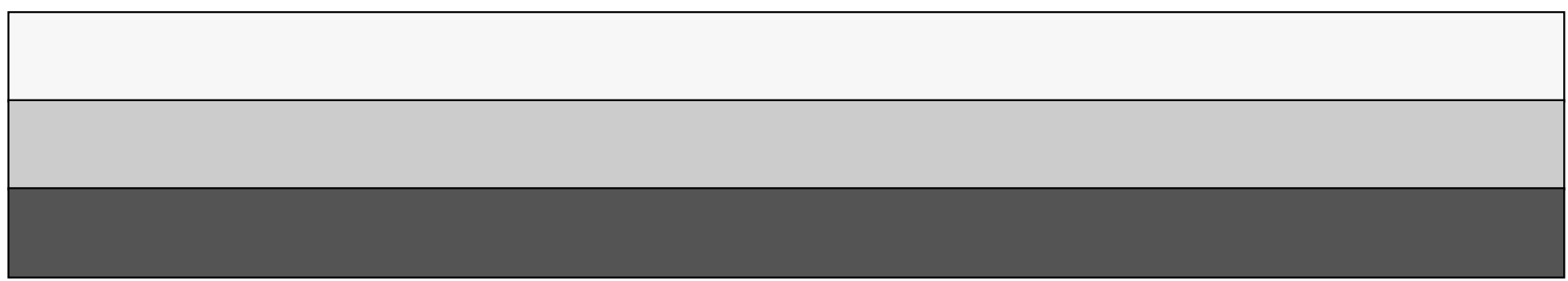

